\title{
Secondary Gob-side Entry Retaining Technology with Double Side Roof Cutting and Pressure Relief in Thin Coal Seam
}

\author{
Luying Shao, Bingxiang Huang*, Xinglong Zhao \\ State Key Laboratory of Coal Resources and Safe Mining, China University of Mining and Technology, Xuzhou, China \\ Email address: \\ shaoluying@126.com (Luying Shao), huangbingxiang@cumt.edu.cn (Bingxiang Huang), xinglongzhao@cumt.edu.cn (Xinglong Zhao) \\ ${ }^{*}$ Corresponding author
}

To cite this article:

Luying Shao, Bingxiang Huang, Xinglong Zhao. Secondary Gob-side Entry Retaining Technology with Double Side Roof Cutting and Pressure Relief in Thin Coal Seam. International Journal of Oil, Gas and Coal Engineering. Vol. 8, No. 5, 2020, pp. 91-102.

doi: 10.11648/j.ogce.20200805.11

Received: August 31,2020; Accepted: September 14, 2020; Published: September 23, 2020

\begin{abstract}
In order to solve the problems of stress concentration and large deformation of surrounding rock of secondary gob-side entry retaining in thin coal seam caused by hard overhanging roof, the method of cutting off overhanging roof on both sides of roadway by manual pre-cutting seam is adopted. It can transfer high stress to goaf on both sides of roadway and reduce roadway deformation. The mechanism of roadway formation, the conditions of double side overhanging roof subsidence and the stress reduction of roadway side support of secondary gob-side entry retaining after double side roof cutting are given. This paper studies the pressure relief law of secondary gob side entry retaining after double side roof cutting in thin coal seam. After double side roof cutting, the stress of roadway side support is reduced by $76 \%$, the maximum vertical displacement of roof is reduced by $84 \%$, and high stress is transferred to goaf. The influence of different double side roof cutting thickness and angle on the pressure relief effect is analyzed. On the premise that the collapsed gangue can fill the goaf, the smaller the thickness of double side roof cutting is, the better the pressure relief effect is, and the greater the double side roof cutting angle is, the better the pressure relief effect is. It has been successfully applied in the left five roadway of No. 69 coal seam in Xinqiang coal mine, and the deformation of roof and floor is reduced by $47 \%$ and the deformation of two sides is reduced by $56 \%$ after double side roof cutting. It has important reference value for the future secondary gob-side entry retaining.
\end{abstract}

Keywords: High Stress, Mining Influence, Double Side Roof Cutting, Secondary Gob-side Entry Retaining, Stress Transfer

\section{Introduction}

The secondary gob-side entry retaining refers to retaining the gob-side entry again after reusing gob-side entry. The secondary gob side entry retaining can be used as a return air roadway in the mining face of the adjacent coal seam, which has a significant effect on gas control in the adjacent coal seam. However, under the influence of repeated mining, the deformation degree of secondary gob-side entry retaining is intensified. The results show that the structure and stress distribution of surrounding rock of roadway are optimized by using double side roof cutting and pressure relief, which can effectively reduce the influence of double side overhanging roof structure and mining stress on roadway, transfer high stress to goaf, and improve roadway stability.

Presplitting blasting, hydraulic fracturing are common roadway pressure relief technology [1]. Scholars at home and abroad have made many significant achievements in the above aspects. Deep hole presplitting blasting can effectively reduce the length of the overhanging roof on the gob side of the roadway, which is conducive to the long-term stability of the roadway [2]. By optimizing the drilling parameters of deep hole blasting, the effect of roof cutting and pressure relief is enhanced [3, 4]. On the basis of deep hole blasting, the mechanism of roof cutting and presplitting blasting of no pillar and roadway formed automatically are systematically studied. 
The distribution law of vertical stress, periodic weighting and shear stress of surrounding rock under one side roof cutting state and non-cutting state is studied by numerical simulation [5-7]. Based on the theoretical analysis, the criterion conditions of the breakthrough between holes and the analytical solution of the stress of the roof cutting short arm structure are obtained, and the rotation angle range of the key block stability is determined [8-10]. Through numerical simulation and theoretical analysis, the key parameters such as the length of the slit, the angle of the slit, the fracture position of the short arm beam and the support are determined [11-14]. The technology of no pillar and roadway formed automatically was the first to carry out production test in 2422 mining face of Baijiao Coal Mine [15], and then the successful test was carried out under the field conditions of thick coal seam, thin coal seam with weak broken surrounding rock, shallow thin coal seam under broken roof, medium thick coal seam under composite roof, poor roadway stability and hard roof [12, 16, 17]. With the development of hydraulic fracturing technology, it has been applied to roof cutting and pressure relief of gob-side entry, so as to control the large deformation of the gob-side entry. Through theoretical analysis, the pressure relief effect of different breaking location of the overhanging roof is discussed, and the optimum breaking location of the overhanging roof is determined [18-20]. Directional slots in the hole can effectively promote the directional initiation and propagation of fracture, so that accurate construction can be carried out after the optimum breaking location of the overhanging roof is determined.

The focus of the above research is once gob-side entry retaining and to control large deformation of gob-side entry, but no in-depth study on roof cutting and pressure relief of secondary gob side entry retaining is conducted. In this paper, left five roadway of No. 69 coal seam in Xinqiang coal mine as the research background, based on the stage deformation law of surrounding rock of secondary gob-side entry retaining without roof cutting, the conditions of double side overhanging roof subsidence and the stress reduction of roadway side support are given. The stress transfer law of secondary gob-side entry retaining after double side roof cutting in thin coal seam is studied. The influence of different thickness and angle of double side roof cutting on pressure relief effect is analyzed. It has been successfully applied in Xinqiang coal mine and achieved good results.

\section{Stress Distribution and Deformation Characteristics of Secondary Gob-side Entry Retaining without Roof Cutting in Thin Coal Seam}

\subsection{Geological Conditions and Production Conditions}

The left five mining face and left six mining face of No. 69 coal seam in Xinqiang coal mine are adjacent to each other (Figure 3(a)). The distance between No. 68 coal seam and No. 69 coal seam is relatively close $(15 \mathrm{~m})$. The gas content of No. 68 coal seam is high, and that of No. 69 coal seam is low. First, the No. 69 coal seam is mined as the liberation layer of No. 68 coal seam, and then the secondary gob-side entry retaining is carried out for the No. 69 coal seam roadway. The secondary gob-side entry retaining is a return air roadway in the corresponding mining face of No. 68 coal seam, so as to better control the gas in No. 68 coal seam, prohibit personnel from entering, and allow a certain degree of deformation.

The average dip angle of the coal seam in the two mining faces is $3^{\circ}$ and the coal seam is relatively stable. The buried depth of the coal seam is $812-844 \mathrm{~m}$, with an average of $828 \mathrm{~m}$. The comprehensive column diagram of borehole in mining face is shown in Figure 1; the physical and mechanical parameters of No. 69 coal seam and its roof and floor are shown in Table 1.

The roadway of the left five mining face of No. 69 coal seam is arranged along the coal seam strike, and the open-off cut is arranged along the inclined direction of the coal seam. The inclined length of the left five mining face and the left six mining face of No. 69 coal seam are $140 \mathrm{~m}$. The left five roadway of No. 69 coal seam is secondary gob-side entry retaining, with a total length of $940 \mathrm{~m}$ and rectangular cross-section. The specification is: width $\times$ height $=4.5 \times 2.3 \mathrm{~m}^{2}$. The support mode is double row anchor cable support.

\begin{tabular}{|c|c|c|}
\hline Columnar & Thickness & Lithology \\
\hline 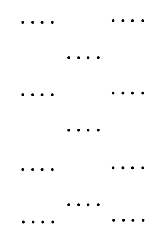 & $7.15 \mathrm{~m}$ & Siltstone \\
\hline & $1.50 \mathrm{~m}$ & No.68 coal seam \\
\hline $\begin{array}{lll} & \cdots & \cdots \\
\cdots & \cdots & \cdots\end{array}$ & $2.10 \mathrm{~m}$ & Fine sandstone \\
\hline $\begin{array}{ccc}\cdots & \ldots & \ldots \\
& \ldots & \ldots \\
\cdots & \ldots & \\
\cdots\end{array}$ & $2.90 \mathrm{~m}$ & Fine powder interbedding \\
\hline $\begin{array}{ccc} & \ldots & \ldots \\
\ldots & \ldots & \ldots \\
\ldots & \cdots & \ldots\end{array}$ & $2.0 \mathrm{~m}$ & Sandy conglomerate \\
\hline $\begin{array}{cccc}\cdots & \ldots & \ldots \\
& \ldots & \ldots \\
\cdots & \ldots & \cdots \\
\cdots & \cdots & \cdots \\
\cdots & \cdots & \cdots\end{array}$ & $6.3 \mathrm{~m}$ & Fine sandstone \\
\hline $\begin{array}{lllll}\cdots & \cdots & \cdots\end{array}$ & $2.0 \mathrm{~m}$ & Siltstone \\
\hline & $1.20 \mathrm{~m}$ & No.68 coal seam \\
\hline 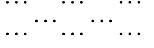 & $2.50 \mathrm{~m}$ & Fine sandstone \\
\hline
\end{tabular}

Figure 1. Comprehensive column diagram of borehole in mining face. 
Table 1. Physical-mechanical parameters of coal and rock strata.

\begin{tabular}{|c|c|c|c|c|c|c|c|c|c|}
\hline Rock stratum & Lithology & $\begin{array}{l}\text { Natural apparent } \\
\text { density }\left(\mathrm{Kg} / \mathrm{m}^{3}\right)\end{array}$ & $\begin{array}{l}\text { Tensile } \\
\text { strength } \\
\text { (MPa) }\end{array}$ & $\begin{array}{l}\text { Compressive } \\
\text { strength } \\
\text { (MPa) }\end{array}$ & $\begin{array}{l}\text { Elastic } \\
\text { modulus } \\
(\mathrm{MPa})\end{array}$ & $\begin{array}{l}\text { Poisson's } \\
\text { ratio }(\mu)\end{array}$ & $\begin{array}{l}\text { Cohesion } \\
\text { (MPa) }\end{array}$ & $\begin{array}{l}\text { Internal } \\
\text { friction } \\
\text { angle }\left(^{\circ}\right)\end{array}$ & $\begin{array}{l}\text { RQD } \\
(\%)\end{array}$ \\
\hline $\begin{array}{l}\text { Strata above main roof of No. } 69 \\
\text { Coal seam }\end{array}$ & Sandy conglomerate & 2534 & 8.5 & 59.30 & 6304 & 0.17 & 10.2 & 31 & 71 \\
\hline Main roof of No. 69 coal seam & Fine sandstone & 2595 & 10.8 & 75.50 & 12100 & 0.1 & 23.6 & 47 & 81 \\
\hline Direct roof of No. 69 coal seam & Siltstone & 2550 & 9 & 50.81 & 7501 & 0.31 & 7.2 & 32 & 72 \\
\hline No. 69 coal seam & Coal & 1347 & 1.35 & 15.86 & 3725 & 0.3 & 2.05 & 55 & 61 \\
\hline No. 69 coal seam direct floor & Mudstone & 2579 & 2.71 & 42.69 & 11396 & 0.25 & 5.6 & 56 & 67 \\
\hline
\end{tabular}

\subsection{Periodic Deformation of Surrounding Rock of Secondary Gob-side Entry Retaining without Roof Cutting}

The surrounding rock of secondary gob-side entry retaining without roof cutting will have large deformation, which will affect the later use of roadway. In the second gob-side entry retaining process without roof cutting in the left four roadway of No. 69 coal seam, the roadway has large deformation, as shown in Figure 2.

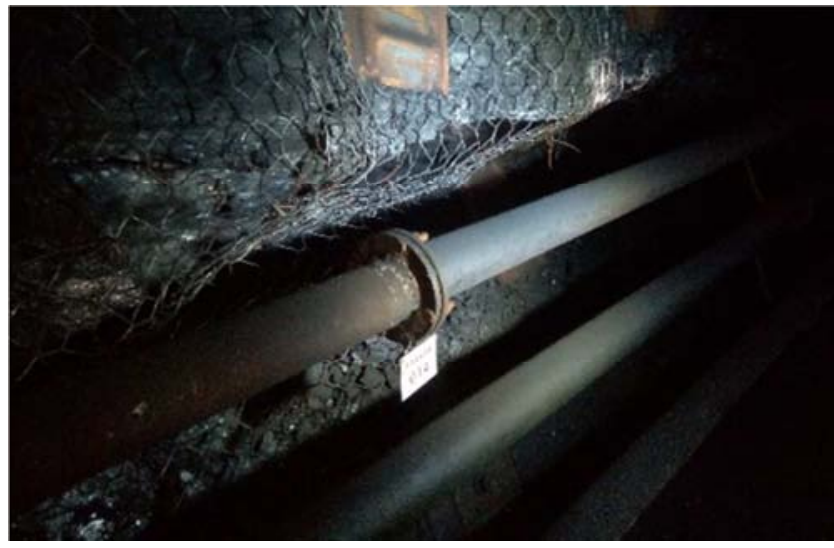

Figure 2. Large deformation occurred in the roadway.

The deformation of surrounding rock during the second gob-side entry retaining without roof cutting of the left fifth roadway in No. 69 coal seam is divided into four stages.

The first stage: the first mining influence stage. As shown in the A-A and B-B sections in Figure 3, along with the mining of the mining face, the hard and complete main roof breaks, forming three key blocks, namely key block A, key block B and key block $\mathrm{C}$. The length $L$ of key block B can be obtained by the following formula [21].

$$
L=l^{\prime}\left(-\frac{l^{\prime}}{S}+\sqrt{\frac{l^{\prime 2}}{S^{2}}+\frac{3}{2}}\right)
$$

Where $S$ is the length of the mining face and $l$ is the periodic weighting step, which is determined by actual measurement or by the following formula [22].

$$
l^{\prime}=h \sqrt{\frac{R_{t}}{3 q}}
$$

Where $R_{\mathrm{t}}$ and $q$ are tensile strength and load of main roof rock respectively. The horizontal distance $L_{2}$ between the main roof fracture point and the coal side of gob-side entry retaining can be obtained by the following formula [23].

$$
L_{2}=\frac{\lambda m}{2 \tan \varphi_{0}} \ln \left[\frac{k \gamma H+\frac{c_{0}}{\tan \varphi_{0}}}{\frac{c_{0}}{\tan \varphi_{0}}+\frac{p_{x}}{\lambda}}\right]
$$

Where $\lambda$ is the side pressure coefficient, $\varphi_{0}, c_{0}$ are the internal friction angle and adhesion of the interface between the coal seam and the roof and floor rock stratum, $K$ is the stress concentration factor, $\gamma$ is the average gravity of overburden, $h$ is the buried depth of the coal seam, and $P_{\mathrm{x}}$ is the support strength of the coal side. The stress of the surrounding rock of the roadway is redistributed, the stress concentration of the goaf side of the roadway is obvious, and the surrounding rock has obvious plastic deformation.

The second stage: the once gob-side entry retaining stable stage. As shown in the C-C section in Figure 3, after mining for a certain distance, the movement of the main roof over the roadway gradually gentle, the stress redistribution is basically completed. The surrounding rock deformation is reduced.

The third stage: the second mining influence stage. As shown in the D-D and E-E sections in Figure 3, with the mining of the mining face on the other side of the roadway, the hard and complete main roof on the other side of the roadway begins to sink, forming a hollow roof area outside the roadway side support body, squeezing the roadway roof and the roadway side support body. At this time, both sides of the roadway have formed hollow roof area, which increases the extrusion degree of roadway roof and roadway side support. The stress of surrounding rock of roadway is redistributed, the side stress concentration of roadway goaf is obvious. The surrounding rock has obvious plastic deformation, and the deformation is large, which increases the support difficulty, affects the use of roadway, and cannot achieve the goal of second gob-side entry retaining.

The fourth stage: the second gob-side entry retaining stable stage. As shown in the F-F section in Figure 3, after the second mining face is mined for a certain distance, the movement of the main roof over the roadway is gradually gentle, the stress redistribution is basically completed, and the surrounding rock deformation is reduced. 
(a)

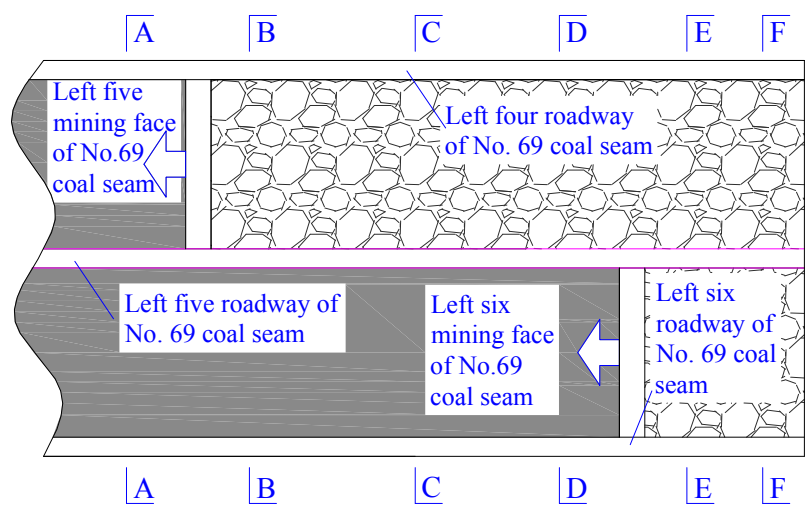

(c)

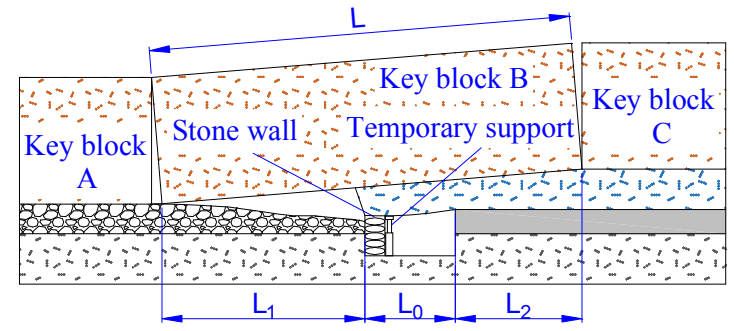

(b)

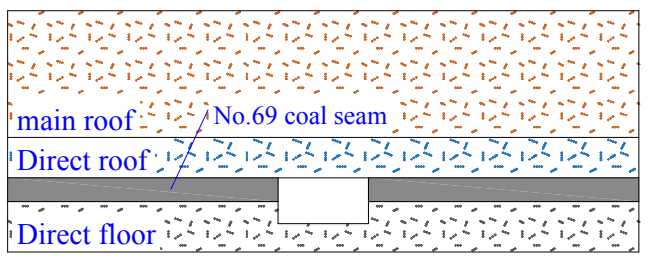

(d)

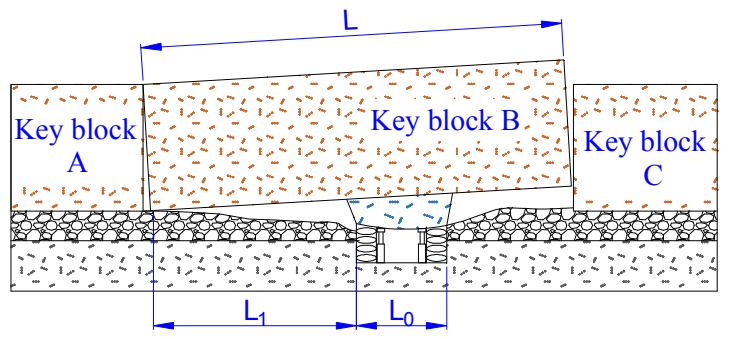

Figure 3. Position relationship of gob side entry retaining without roof cutting: (a) plan; (b) A-A section (c) Section B-B, $C$-C, D-D (the three sections are the same); (d) Section E-E and F-F (both sections are the same).

\section{Theoretical Analysis and Technological Process of Secondary Gob-side Entry Retaining with Double Side Roof Cutting}

\subsection{Roadway Formation Mechanism of Secondary Gob-side Entry Retaining with Double Side Roof Cutting}

Before the first mining face is mined, the presplitting blasting is carried out in advance on the corresponding side of the roadway. As shown in Figure 4 (b), when the first mining face passes through the starting point of presplitting for a period of time, the roof within the presplitting range will completely fill the goaf. When the overlying roof compacts the collapsed gangue, due to the bending and sinking of the roadway roof to a certain extent, the edge of the gangue belt in the goaf and the main roof above the roadway hard side break, forming key blocks a, B and C. After mining for a period of time, the gangue in the goaf is compacted. The key blocks A, $\mathrm{B}$ and $\mathrm{C}$ above the roadway are hinged with each other, forming an arch structure for the first time, and the surrounding rock of the roadway is gradually stable.

Before the mining of the second mining face, the second roof cutting is carried out at the starting point of the first presplitting blasting. As shown in Figure 4 (c), when the second mining face passes through the starting position of presplitting for a period of time, because the main roof above the roadway has fractured at the side of the second mining face, the key block C starts to sink. At the same time, due to the second roof cutting, the gangue within the scope of the second roof cutting collapses and fills the goaf. The gangue on the top side of the second roof cutting is compacted. The key blocks A, $\mathrm{B}$ and $\mathrm{C}$ above the roadway are hinged with each other again, forming arch structure for the second time, and surrounding rock of roadway is stable again.

Compared with the secondary gob-side entry retaining without roof cutting, the secondary gob-side entry retaining with double side roof cutting has the following advantages. Due to the double side roof cutting effect, the collapsed gangue provides a certain degree of support to the key block B above the roadway, slows down the sinking speed of the key block B, and avoids the roadway collapse caused by the sudden falling of the main roof. At the same time, the vertical displacement of key block B is reduced, and the roof subsidence of roadway is reduced. However, considering the overall stability of the roadway, the secondary gob-side entry retaining with double side roof cutting is only applicable to thin coal seam; and the reused secondary gob-side entry retaining is only used as a return air roadway of the corresponding mining face in the adjacent coal seam to control the gas and prohibit personnel from entering. 


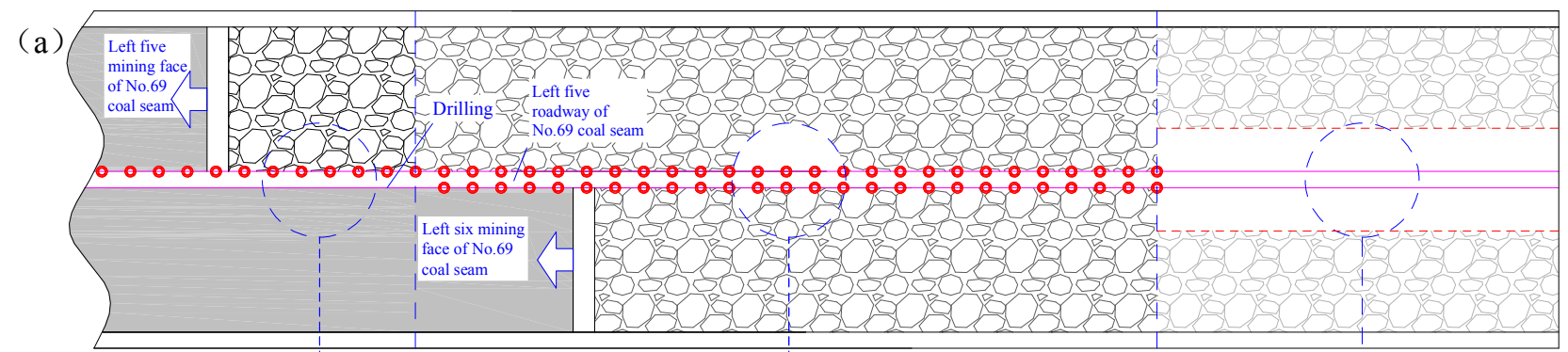

(b)

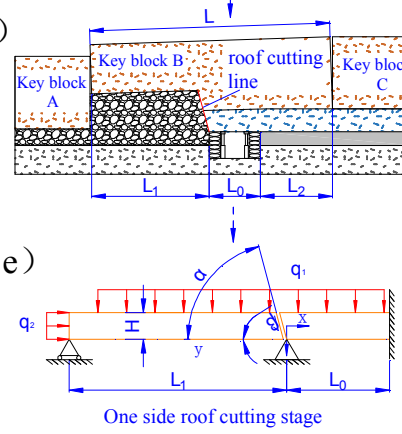

(c)

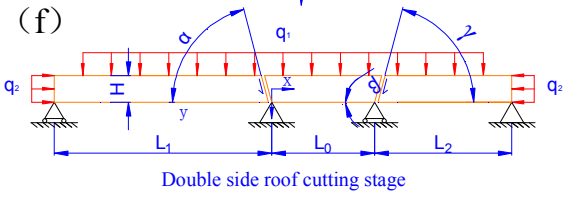

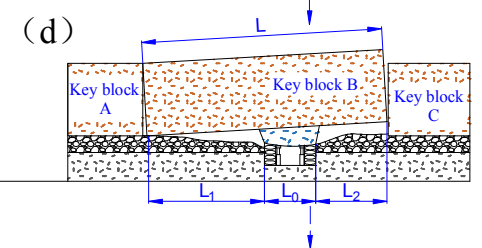

$(\mathrm{g})$

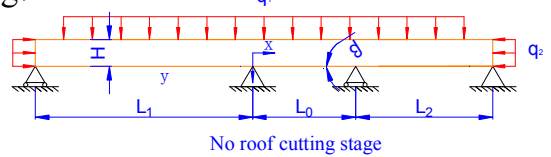

Figure 4. Principle of double side roof cutting.

\subsection{Conditions of Overhanging Roof Subsidence and Stress of Roadway Side Support}

According to the different connection state between the roof and the supporting structure, it can be divided into one side roof cutting state, double side roof cutting state and No roof cutting state. The stress of the roof is simplified, and the stress analysis of the roof at different stages is carried out, as shown in Figure 4.

As shown in Figure 4(f), at the section of the borehole, due to the mutual extrusion of the two roof, there is a positive pressure, which forms a large friction resistance on the section. When the overhanging roof load is less than the friction force, the roof cannot collapse in time, and will squeeze the roof above the roadway, forming a large stress concentration, increasing the difficulty of roadway support. When the overhanging roof load is greater than the friction force, the roof of the goaf can sink smoothly at the Section [24]. According to the theory of material mechanics, it can be concluded that:

$$
\begin{aligned}
\frac{q_{1} \sin \alpha \cdot\left(L-L_{2}-L_{0}\right) \cos \beta}{2 \sin \alpha} & +\frac{q_{2} \cos \alpha \cdot\left(L-L_{2}-L_{0}\right) \cos \beta}{2 \sin \alpha}>\mu\left[\frac{q_{2} \sin \alpha \cdot H}{\sin (\alpha-\beta)}-\frac{q_{1} \cos \alpha \cdot H}{\sin (\alpha-\beta)}\right] \\
& \frac{q_{1} \sin \gamma \cdot L_{2} \cdot \cos \beta}{2 \sin \gamma}+\frac{q_{2} \cos \gamma \cdot L_{2} \cdot \cos \beta}{2 \sin \gamma} \\
& >\mu\left[\frac{q_{2} \sin \gamma \cdot H}{\sin (\gamma-\beta)}-\frac{q_{1} \cos \gamma \cdot H}{\sin (\gamma-\beta)}\right]
\end{aligned}
$$

Where $q_{1}$ is horizontal load, $\alpha$ is left cutting angle; $L_{0}$ is roadway width, $L_{1}$ is left hanging roof length, $\beta$ is coal seam dip angle, $q_{2}$ is vertical load, $\mu$ friction coefficient is $0.5 ; H$ is double side roof cutting thickness; $\gamma$ is right roof cutting angle.

The stress of the side support and roof structure in the state of double side roof cutting is analyzed (Figure 4). According to the theory of mechanics of materials, the stress of the supporting body on both sides of roadway is symmetrical, and its value is:

$$
F_{1}=F_{2}=\frac{q_{1} L_{0}}{2}
$$

The stress analysis of roadway side support and roof structure under the condition of double side overhanging roof is carried out (Figure 4). According to the theory of material mechanics, the stress of the supporting body on both sides of roadway is symmetrical, and its value is:

$$
\begin{aligned}
& F_{1}=\frac{q_{1}\left(L_{0}+L_{1}\right)}{2} \\
& F_{2}=\frac{q_{1}\left(L_{0}+L_{2}\right)}{2}
\end{aligned}
$$

Compared with the double side overhanging roof, the stress of the side support of the two sides of the roadway with the double side roof cutting is reduced by $\frac{q_{1}\left(L-L_{0}-L_{2}\right)}{2}$ and $\frac{q_{1} L_{2}}{2}$ respectively.

\subsection{Secondary Gob-side Entry Retaining Technology Process with Double Side Roof Cutting}

The core of the technology of secondary gob-side entry retaining technology with double side roof cutting lies in the sequence of twice roof cutting and the relationship between the position of two times of roof cutting and the position of adjacent mining face on both sides.

(1) Roof cutting for the first time

Before the advance support of the left five mining face of the No. 69 coal seam drilling and blasting were carried out on the roof of the mining face side (Figure 4). Before blasting, the roadway within $20 \mathrm{~m}$ around the blasting site shall be 
reinforced.

(2) Roof cutting for the second time

With mining of the left five mining face of the No. 69 coal seam, the starting position of the first roof cutting enters the rear of the left five mining face of the No. 69 coal seam. Due to the effect of blasting presplitting, the overhanging roof on the left five mining face of the No. 69 of roadway gradually collapses and compacts and stabilizes. At this time, the roof of the other side is cut at the starting position of the first roof cutting (Figure 4). The second roof cutting position should be in front of the advance support of the left six mining face in the No. 69 coal seam. Similarly, before blasting, the roadway within the scope of $20 \mathrm{~m}$ before and after the blasting site is reinforced.

\section{Analysis of Stress Transfer Law and Influencing Factors of Double Side Roof Cutting}

\subsection{Establishment of Numerical Model}

Using FLAC $^{3 \mathrm{D}}$, six cuboid numerical models with the size of $46.5 \mathrm{~m} \times 14 \mathrm{~m} \times 12 \mathrm{~m}$ are established (Figure 5). The thickness of each stratum is shown in Figure 1, and the physical and mechanical properties of each stratum are shown in Table 1.

The stress transfer law after double side roof cutting can be analyzed by comparing double side overhanging roof test (Figure 5(a)) and double side roof cutting experiment (Figure 5(b)). Among them, according to the specific engineering geological conditions of the left five mining face of No. 69 coal seam and the left six mining face of No. 69 coal seam in Xinqiang coal mine, the physical and mechanical parameters

(a)
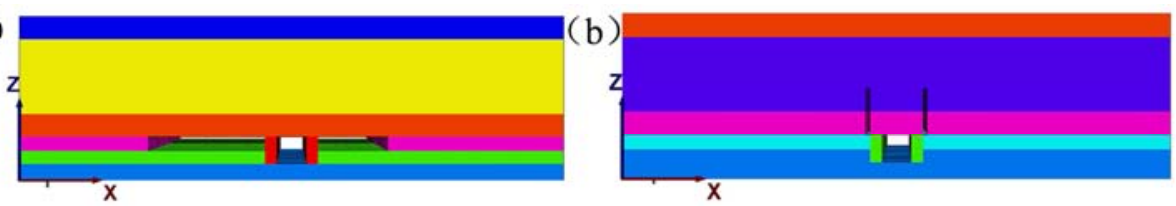

(c)
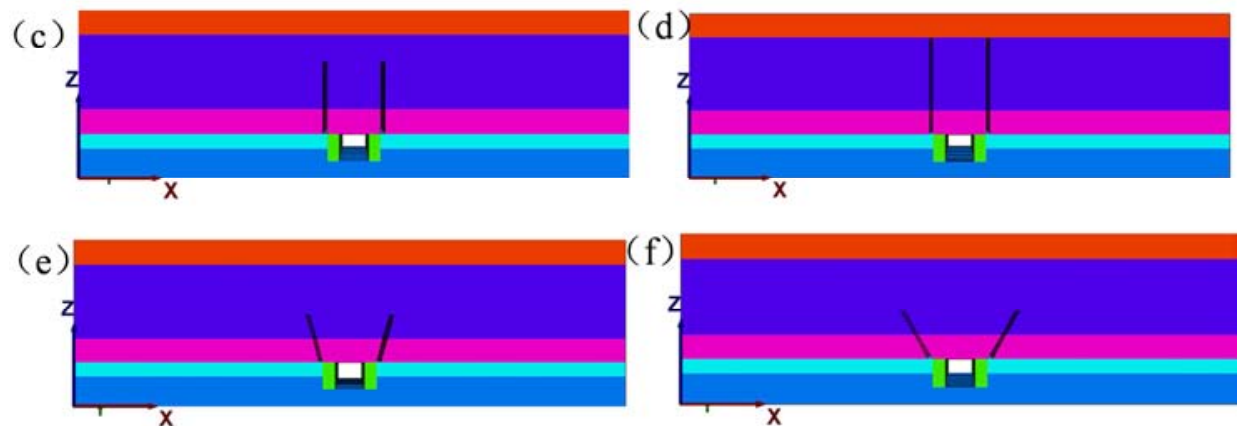

of coal and rock strata (Table 1) and (1), (2), (3), the overhanging roof on both sides of roadway in the numerical model can be determined as $10 \mathrm{~m}$ and $6 \mathrm{~m}$ respectively.

Double side roof cutting experiment (Figure 5(b)), moderate double side roof cutting thickness experiment (Figure 5(c)) and larger double side roof cutting thickness experiment (Figure 5 (d)) can be used to analyze the influence of double side roof cutting thickness on stress transfer effect. In the numerical model, the basis of double side roof cutting thickness is as follows: firstly, according to the principle that the gangue under roof collapse can fill the goaf, the thickness of double side roof cutting can be determined by the following formula.

$$
d=\frac{h}{(\mathrm{k}-1)}=4 \mathrm{~m}
$$

Where $d$ is the thickness of double side roof cutting, $h$ is the mining height, and $k$ is the coefficient of rock fragmentation expansion (1.3). In addition, according to the thickness of the main roof of the left five mining face and the left six mining face of No. 69 coal seam, the thickness of the double side roof cutting is determined to be $8.3 \mathrm{~m}$. Finally, the thickness of double side roof cutting was $6 \mathrm{~m}$ as a comparative experiment.

The results show that the effects of double side roof cutting angle on stress transfer effect can be analyzed by comparing double side roof cutting experiment (Figure 5(b)), moderate double side roof cutting angle experiment (Figure $5(\mathrm{e})$ ) and small double side roof cutting angle experiment (Figure 5(f)). The double side roof cutting angles were 60 degrees, 75 degrees and 90 degrees respectively.

Figure 5. Numerical model: (a) double side overhanging roof (b) double side roof cutting (the roof cutting thickness is $4 m$ and the roof cutting angle is $90{ }^{\circ}$ ) (c) moderate double side roof cutting thickness (the roof cutting thickness is 6m and the roof cutting angle is $90^{\circ}$ )(d) larger double side roof cutting thickness (the roof cutting thickness is $8 m$ and the roof cutting angle is $90^{\circ}$ ) (e) moderate double side roof cutting angle (roof cutting angle $75^{\circ}$ and roof cutting thickness $4 m$ ) (f) small double side roof cutting angle experiment (roof cutting angle $60^{\circ}$ and roof cutting thickness $4 \mathrm{~m}$ ).

\subsection{Stress Transfer Law of Double Side Roof Cutting}

The vertical stress and vertical displacement nephogram of roadway roof in double side roof cutting experiment (Figure $5(\mathrm{~b})$ ), moderate double side roof cutting thickness experiment (Figure 5(c)) and larger double side roof cutting thickness 
experiment (Figure 5(d)) are shown in Figure 6. The vertical displacement contrast curve of roadway roof is shown in

(a)

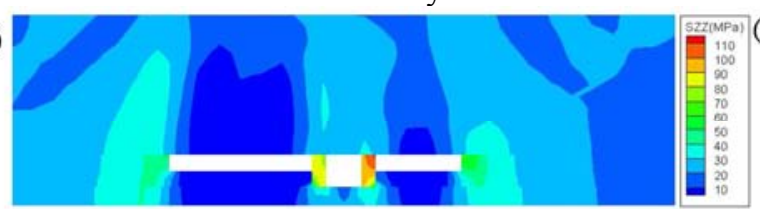

(c)

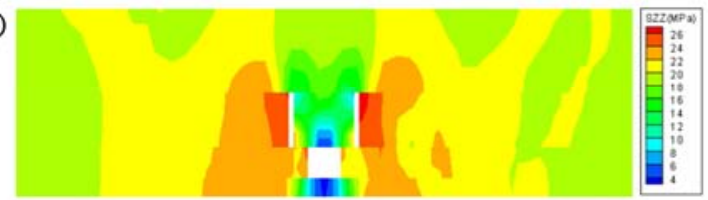

Figure 7.

(b)

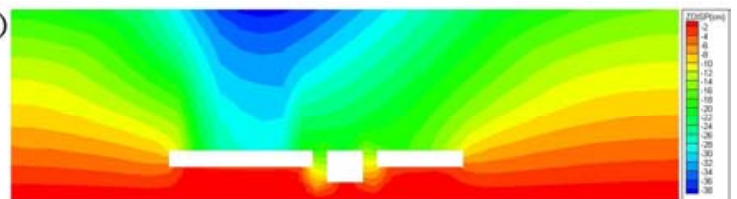

(d)

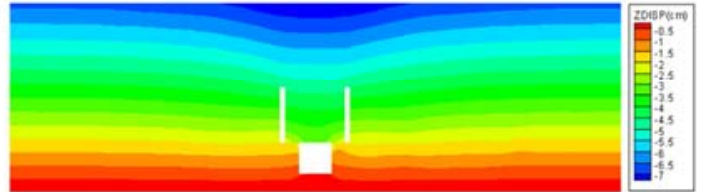

Figure 6. Vertical stress and vertical displacement nephogram of roadway with and without double side roof cutting: (a) Stress nephogram of overhanging roof; (b) Cloud chart of overhanging roof displacement; (c) Nephogram of double side roof cutting stress; (d) Displacement nephogram of double side roof cutting.

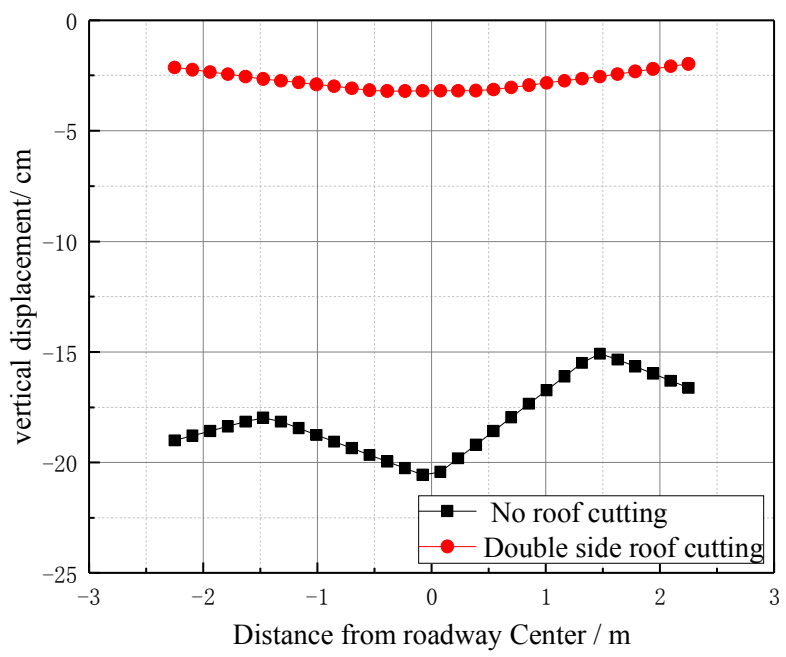

Figure 7. Comparison of vertical displacement curve of roadway roof with and without double side roof cutting.

The stress peak values of the side support body of double side overhanging roof roadway and the double side cutting roof roadway are $115 \mathrm{MPa}$ and $28 \mathrm{MPa}$ respectively. After cutting the roof on both sides, the stress decreased by $76 \%$,

(a)

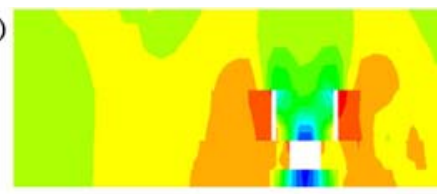

(c)

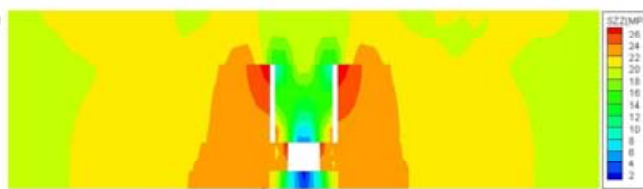

(e)

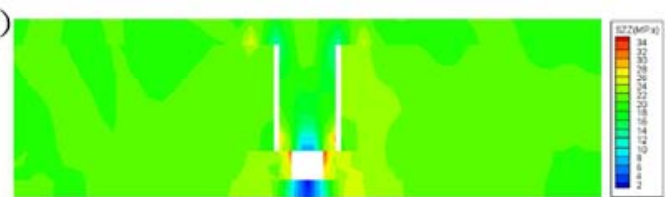

and the stress concentration of the supporting body beside the roadway was obviously relieved, and the high stress was transferred to the goaf.

The maximum vertical displacement of the roof of the roadway without double side roof cutting and that of the roadway with double side roof cutting are $20.6 \mathrm{~cm}$ and 3.2 $\mathrm{cm}$ respectively. After double side roof cutting, the maximum vertical displacement of roof is reduced by $84 \%$, and the roadway deformation is significantly reduced by double side roof cutting and pressure relief.

\subsection{Influence of Double Side Roof Cutting Thickness on Gob-Side Entry Retaining Effect}

The vertical stress and vertical displacement nephogram of roadway roof in double side roof cutting experiment (Figure $5(\mathrm{~b})$ ), moderate double side roof cutting thickness experiment (Figure 5(c)) and larger double side roof cutting thickness experiment (Figure 5(d)) are shown in Figure 8. The vertical displacement contrast curve of roadway roof is shown in Figure 9.

(b)

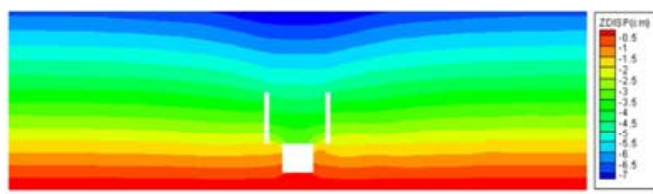

(d)

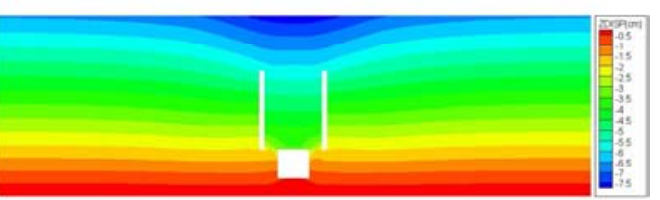

(f)

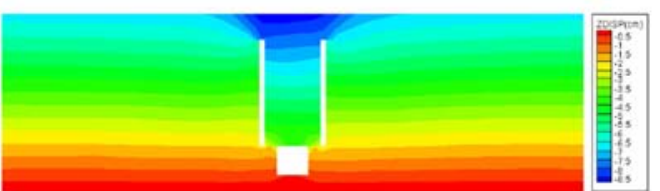

Figure 8. Nephogram of vertical stress and strain distribution after double side roof cutting with different lengths: (a) $4 m$ double side roof cutting stress nephogram (b) $4 m$ double side roof cutting displacement nephogram; (c) 6m double side roof cutting stress nephogram; (d) 6m double side roof cutting displacement nephogram; (e) $8.3 \mathrm{~m}$ double side roof cutting stress nephogram; (f) $8.3 \mathrm{~m}$ double side roof cutting displacement nephogram. 


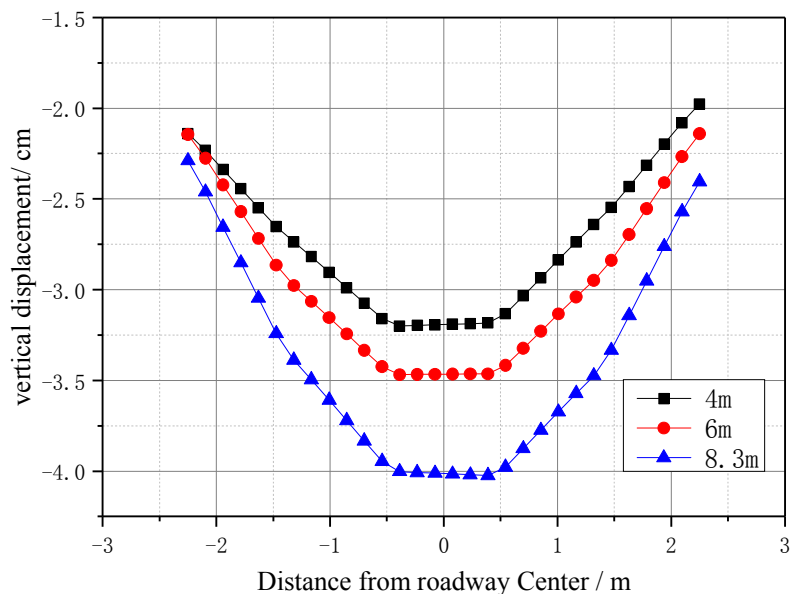

Figure 9. Comparison of vertical displacement curves after double side roof cutting with different lengths.

When the thickness of double side roof cutting is $4 \mathrm{~m}, 6 \mathrm{~m}$ and $8.3 \mathrm{~m}$, the peak stress concentration inside the roadway side support is $28 \mathrm{MPa}, 28 \mathrm{MPa}$ and $35 \mathrm{MPa}$ respectively.

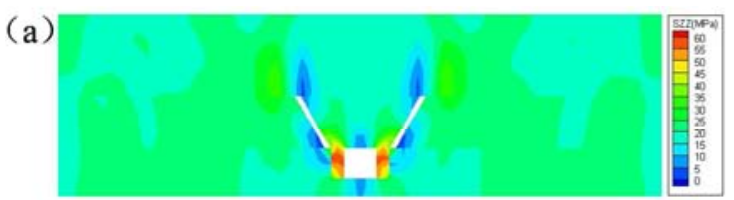

(c)

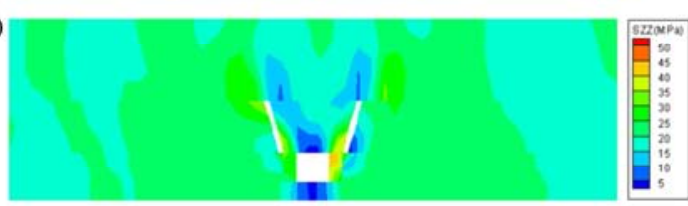

(e)

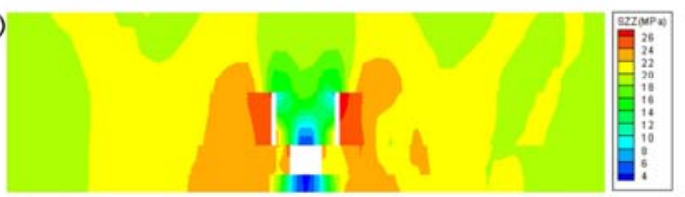

The greater the thickness of double side roof cutting is, the greater the damage of roadway roof is, so the load of support body is increased.

When the thickness of double side roof cutting is $4 \mathrm{~m}, 6 \mathrm{~m}$ and $8.3 \mathrm{~m}$, the maximum vertical displacement of roadway roof is $3.2 \mathrm{~cm}, 3.5 \mathrm{~cm}$ and $4 \mathrm{~cm}$ respectively. The greater the thickness of double side roof cutting, the greater the damage of roadway roof is, so the vertical displacement is increased.

\subsection{Influence of Double Side Roof Cutting Angle on Gob Side Entry Retaining Effect}

The vertical stress and vertical displacement nephogram of roadway roof in double side roof cutting experiment (Figure 5(b)), moderate double side roof cutting angle experiment (Figure 5(e)) and small double side roof cutting angle experiment (Figure 5(f)) are shown in Figure 10. The vertical displacement contrast curve of roadway roof is shown in Figure 11.

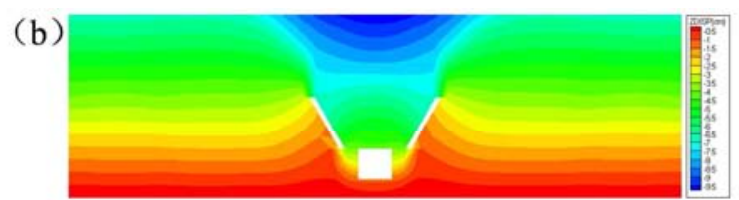

(d)
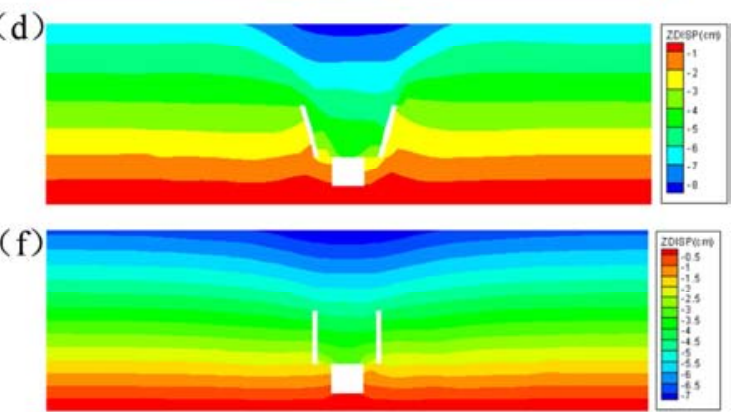

Figure 10. Cloud chart of vertical stress and displacement distribution after double side roof cutting at different angles: (a) $60^{\circ}$ double side roof cutting stress nephogram; (b) $60^{\circ}$ double side roof cutting displacement nephogram; (c) $75^{\circ}$ double side roof cutting stress nephogram; (d) $75^{\circ}$ double side roof cutting displacement nephogram; (e) $90^{\circ}$ double side roof cutting stress nephogram; (f) $90^{\circ}$ double side roof cutting displacement nephogram.

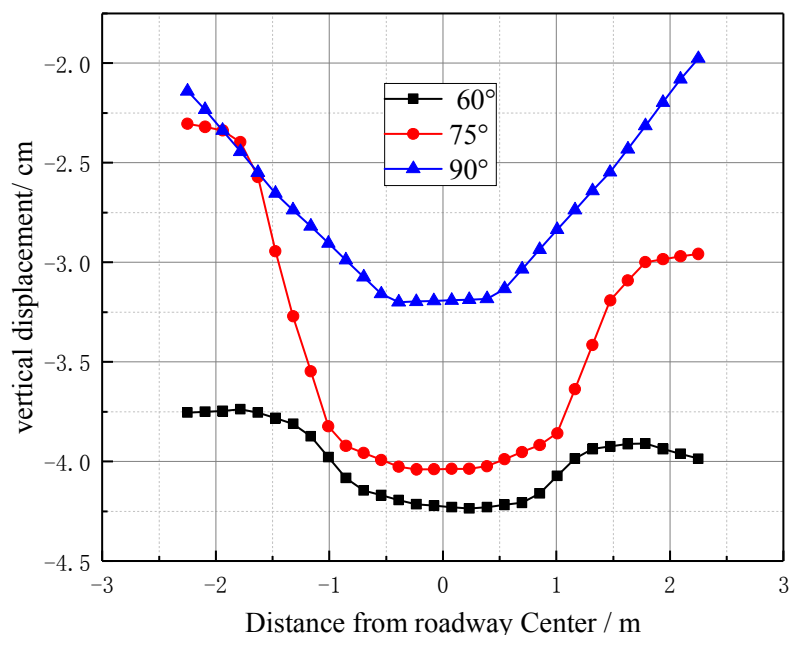

Figure 11. Comparison of vertical displacement of roadway roof after double side roof cutting at different angles.
When the cutting angle of both sides is $60^{\circ}, 75^{\circ}$ and $90^{\circ}$, the peak stress concentration of roadway side support body is $65 \mathrm{MPa}, 55 \mathrm{MPa}$ and $28 \mathrm{MPa}$ respectively. With the increase of double side roof cutting angle, the more obvious the transfer of stress concentration peak to the side of goaf, and the smaller the peak value of stress concentration of roadway side support body, which is conducive to the stability of roadway surrounding rock.

When the roof cutting angle is $60^{\circ}, 75^{\circ}$ and $90^{\circ}$ on both sides, the displacement of roadway roof is $4.3 \mathrm{~cm}, 4 \mathrm{~cm}$ and $3.2 \mathrm{~cm}$. The larger the angle of double side roof cutting is, the smaller the displacement of roadway roof is.

\subsection{Determination of borehole Spacing}

According to the different physical and mechanical parameters of roof strata and the surrounding stress field, the field roof cutting test is carried out. After blasting, the effect 
of roof pre-splitting line is obvious, and there is no obvious damage to the roof, so it is the best roof cutting borehole spacing [25], generally 500 600 $\mathrm{mm}$.

\section{Field Test}

\subsection{Test Scheme}

The 68 coal seam above $240 \mathrm{~m}$ ahead of the left five open-off cut in No. 69 coal seam is not minable, so there is no need for secondary gob-side entry retaining to control gas in 68 coal seam. As shown in Figure 12, before mining the left six mining face of No. 69 coal seam, pre-cutting roof is carried out on the left side of the left five roadway of No. 69 seam ( $240 \mathrm{~m}$ away from the open-off cut). Before mining the left six mining face of No. 69 coal seam, the pre-cutting roof was carried out on the right side of the roadway where the first roof cutting was made.

(1) The roof cutting angles of two sides are $90^{\circ}$ and the length of boreholes of two sides is $4 \mathrm{~m}$ and the diameter of boreholes is $40 \mathrm{~mm}$. According to the field test, the borehole spacing is $0.6 \mathrm{~m} . q_{1}=20 \mathrm{MP}, \alpha=90^{\circ}$, $L_{0}=12 \mathrm{~m}, \beta=3^{\circ}, q_{2}=20 \mathrm{MP}, \mu=0.5, H=4 \mathrm{~m}, \gamma=90^{\circ}$ are brought into the formula (4) and (5) for verification. The calculation results show that $\alpha=90^{\circ}$ and $\gamma=90^{\circ}$

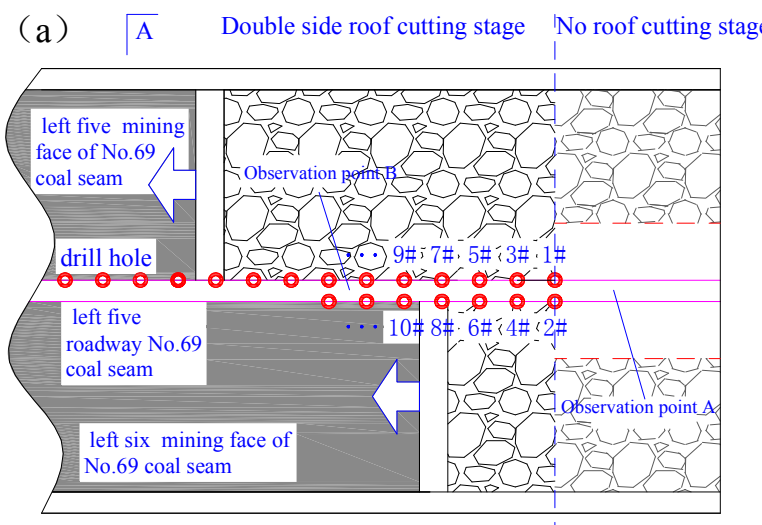

A Double side roof cutting stage $\quad$ No roof cutting stage meet the requirements.

(2) After mining the left five coal mining face in No. 69 seam, the roadway side support body is constructed in time on the left side of the left five roadway of No. 69 seam. After mining the left six mining face of No. 69 seam, the roadway side support body was constructed in time on the right side of the left five roadway of the 69 coal seam. The form of roadway side support is telescopic U-shaped steel and stone wall. The stone wall is $1 \mathrm{~m}$ wide at the top and $1 \mathrm{~m}$ at the bottom. After pre-cutting the roof, the single hydraulic prop is used to temporarily support the roof along the stone wall, and the support is recovered after the roadway is affected by two mining operations.

(3) In order to fix the roof of roadway in stable rock stratum, the length of anchor cable is $8 \mathrm{~m}$.

(4) Before the mining of the two mining faces, observation point A (double side overhanging roof observation point) was set up at $220 \mathrm{~m}$ from the left five open-off cut of No. 69 coal seam, and observation point B (double side roof cutting observation point) was set up at $300 \mathrm{~m}$ away from the left five open-off cut of No. 69 coal seam.

Figure 12. Construction drawing of secondary gob-side entry retaining: (a) plan; (b) profile.

\subsection{Effect Analysis}

By comparing the data measured at observation point $\mathrm{A}$ and observation point $\mathrm{B}$, the effect of double side roof cutting and pressure relief is analyzed.

\subsubsection{Plastic Zone of Roadway Roof}

The integrity of the roof at observation point $A$ and observation point B was observed by borehole peep, as shown in Figure 13. According to Figure 13 (a), it can be determined that the height of the plastic zone of the roof of the double side roof roadway is $2.43 \mathrm{~m}$. According to Figure 13 (b), it can be determined that the height of the plastic zone of the roof of the double side overhanging roof roadway is $2.15 \mathrm{~m}$. The height of plastic zone is less than $0.28 \mathrm{~m}(12 \%)$. (a)
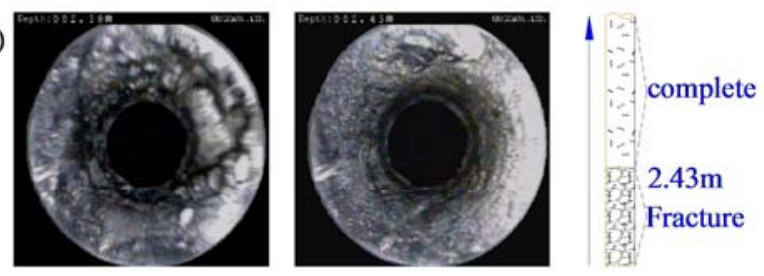

(b)
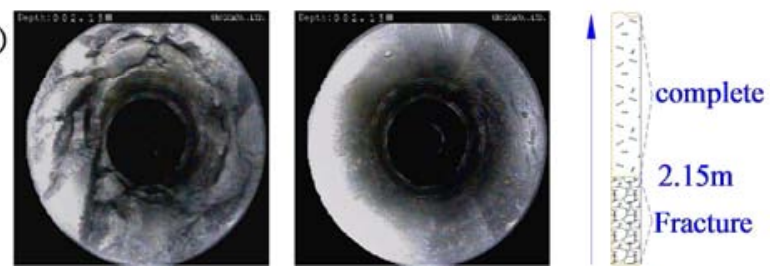

Figure 13. Observation of roof integrity before and after secondary gob-side entry retaining: (a) Observation point A; (b) Observation point $B$. 


\subsubsection{Roadway Deformation}

When the left five mining face of No. 69 coal seam are mined to $200 \mathrm{~m}$ before the observation point, the deformation of roof, floor and two sides of roadway at each observation point (observation point $\mathrm{A}$ and observation point $\mathrm{B}$ ) are recorded. Each record is 15 days apart. The comparison of the displacement of the roof and floor and the two sides of roadway in the two observation points is shown in Figure 14.

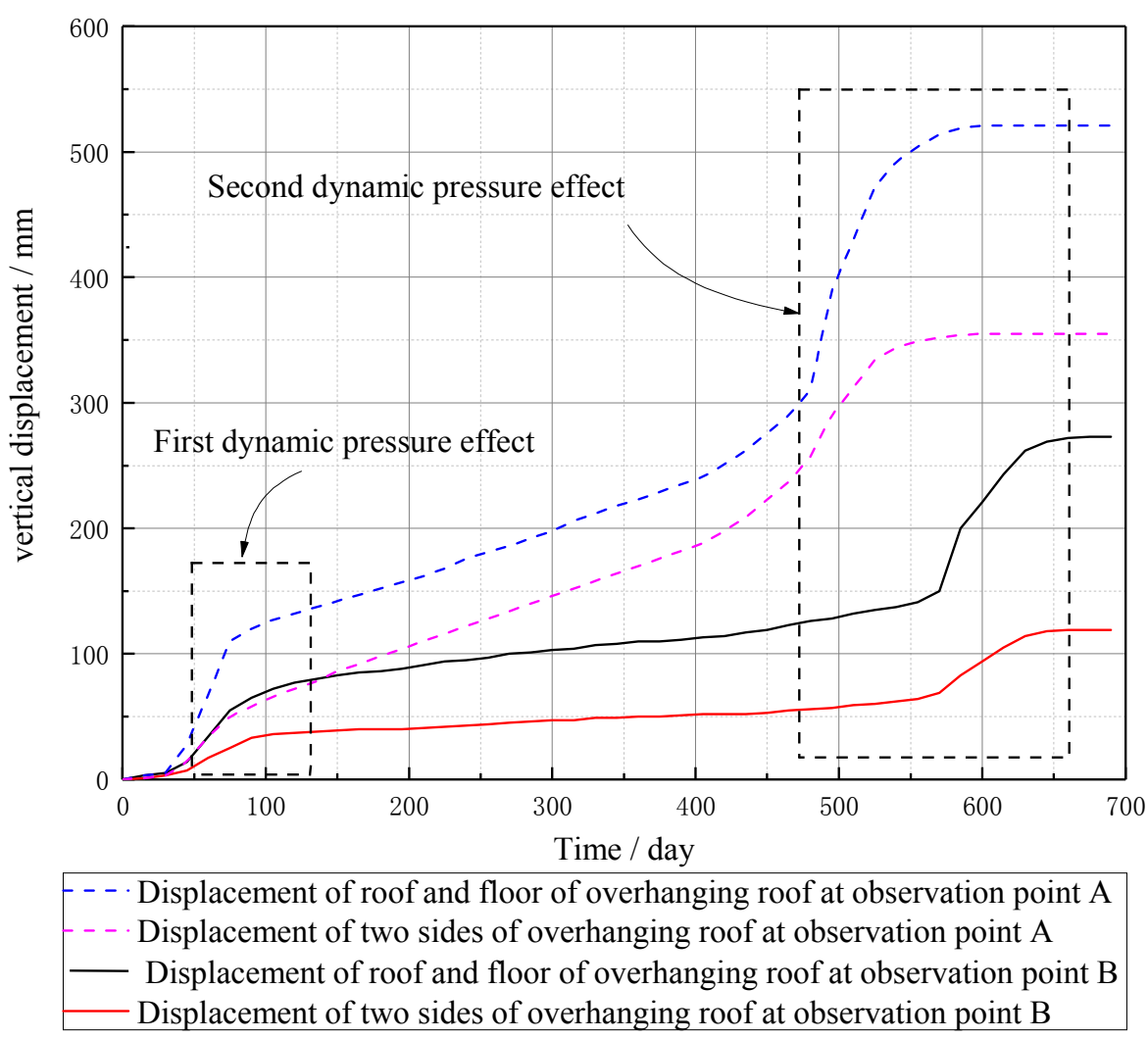

Figure 14. Roadway deformation before and after secondary mining at observation points $A$ and $B$.

By analyzing Figure 14, we can draw the following conclusions:

a. The stability of secondary gob-side entry retaining is greatly affected by twice mining dynamic pressure. Before and after the two mining faces pass through the observation point $\mathrm{A}$ and $\mathrm{B}$, the roadway deformation is the fastest.

b. At observation point $\mathrm{A}$, the maximum displacement of roof and floor is $521 \mathrm{~mm}$, and that of two sides is 355 mm. At observation point $B$, the maximum displacement of roof and floor is $273 \mathrm{~mm}$, and that of two sides is $119 \mathrm{~mm}$. After double side roof cutting, the deformation of roof and floor decreased by $248 \mathrm{~mm}$ $(47 \%)$, and that of two sides decreased by $154 \mathrm{~mm}$ $(56 \%)$. The deformation of roadway can be effectively reduced by using secondary gob-side entry retaining technology with double side roof cutting and pressure relief.

Comprehensive analysis shows that the deformation of most of the left five roadway in No. 69 coal seam is small, the roof deformation is $125-180 \mathrm{~mm}$, the floor deformation is $105-132 \mathrm{~mm}$, the left side deformation is $30-50 \mathrm{~mm}$, the right side deformation is $50-80 \mathrm{~mm}$, and the average section size is more than $4.8 \mathrm{~m}^{2}$, which can meet the use requirements. The effect of secondary gob-side entry retaining is shown in
Figure 15.

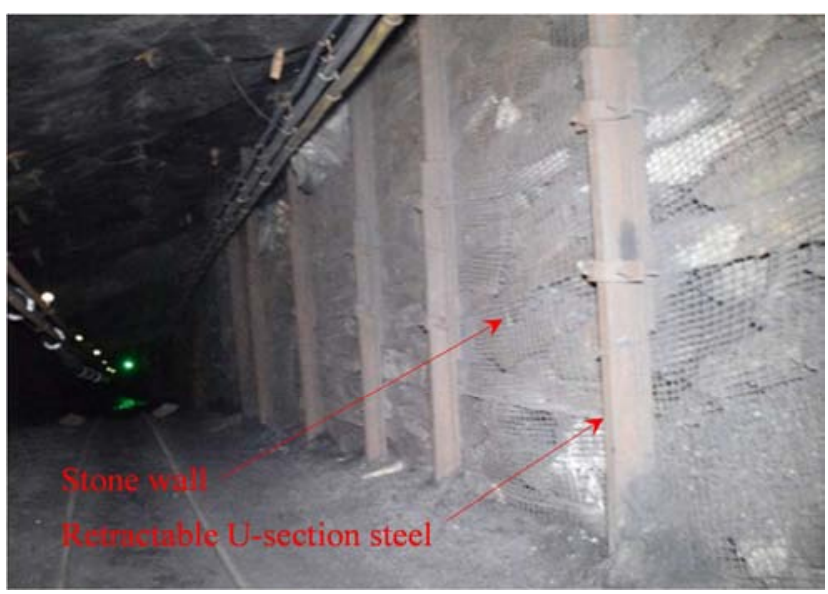

Figure 15. Effect of secondary gob-side entry retaining.

\section{Conclusions}

(1) The secondary gob-side entry retaining technology with double side roof cutting and pressure relief in thin coal seam is put forward. Firstly, the first artificial pre-cutting roof was carried out by explosive blasting before the abutment pressure influence area of the first 
mining face. Then, the second artificial pre-cutting roof is carried out by explosive blasting ahead of the abutment pressure influence area of the second mining face. The results show that the length of the overhanging roof on both sides is reduced, the roof load of gob side entry retaining is reduced, and the impact damage caused by large area sudden roof collapse is avoided. It accelerates the roof fracture and shortens the disturbance time of roof movement. The high stress is transferred to the goaf on both sides of the roadway to realize the stress transfer.

(2) The mechanism of roadway formation, the conditions of double side overhanging roof subsidence and the stress reduction of roadway side support of secondary gob-side entry retaining with double side roof cutting are given.

(3) This paper studies the pressure relief law of secondary gob-side entry retaining with double side roof cutting in thin coal seam. After double side roof cutting, the stress of roadway side support decreases by $76 \%$, and the maximum vertical displacement of roof decreases by $84 \%$. The stress concentration of surrounding rock of roadway has been obviously relieved, and the high stress is transferred to the side of goaf.

(4) The influence of different thickness and angle of double side roof cutting on the pressure relief effect was analyzed. On the premise that the collapsed gangue can fill the goaf, the smaller the thickness of double side roof cutting is, the better the pressure relief effect is, and the greater the double side roof cutting angle is, the better the pressure relief effect is.

(5) The secondary gob-side entry retaining technology with double side roof cutting and pressure relief in thin coal seam has been successfully implemented in the left five roadway of No. 69 coal seam in Xinqiang coal mine. After double side roof cutting, the deformation of roof and floor is reduced by $47 \%$, and the deformation of two sides is reduced by $56 \%$. The secondary gob-side entry retaining have met the use requirements.

\section{Acknowledgements}

Financial support for this work, provided by the National Natural Science Foundation of China (No. 51774272), is gratefully acknowledged.

\section{References}

[1] Li Zhaohua, Tao Zhigang, Meng Zhigang. Longwall mining method with roof-cutting unloading and numerical investigation of ground pressure and roof stability [J]. Arabian Journal of Geosciences, 2018, 11 (22).

[2] Zhao Yiming, Zhang Nong, Zheng Xigui, Li Baoyu. Structural optimization of overlying strata for gob-side entry retaining in $1000 \mathrm{~m}$ deep mine with direct thick and hard roof [J]. Journal of Mining\&Safety Engineering, 2015, 32 (05): 714-720. (in
Chinese).

[3] Zhiyi Zhang, Nong Zhang, Hideki Shimada, Takashi Sasaoka, Sugeng Wahyudi. Optimization of hard roof structure over retained goaf-side gateroad by pre-split blasting technology [J]. International Journal of Rock Mechanics and Mining Sciences, 2017, 100: 330-337.

[4] Konicek Petr, Soucek Kamil, Stas Lubomir, Singh Rajendra. Long-hole destress blasting for rockburst control during deep underground coal mining [J]. Int J Rock Mech Min Sci. 2013, 61: 141-153.

[5] Tao Zhigang, Song Zhigang, He Manchaoi, Meng Zhigang, Pang Shihui. Principles of the roof cut short-arm beam mining method (110 method) and its mining-induced stress distribution [J]. International Journal of Mining Science \& Technology, 2017.

[6] He Manchao, Wang Yajun, Yang Jun, Gang Yubing, Gao Qing, Wang Shibin. Roof cutting and pressure-relief mining method Zonal characteristics and its influence factor with no pillar and roadway formed automaticly [J]. Journal of China University of Mining \& Technology, 2018, 47 (06): 1157-1165 (in Chinese).

[7] He Manchao, Ma Xingen, Wang Jiong, Zhang Jiabin, Liu Yuxing. Feature analysis of working face strata pressure with roof cutting pressure releasing in medium-thick seam and compound roof condition [J]. Chinese Journal of Rock Mechanics and Engineering, 2018, 37 (11): 2425-2434. (in Chinese)

[8] He Manchao, Guo Pengfei, Zhang Xiaohu, Wang Jiong. Directional pre-splitting of roadway roof based on the theory of bilateral cumulative tensile explosion [J]. Exploslon and Shock Waves, 2018, 38 (04): 795-803. (in Chinese)

[9] Jianning Liu, Manchao He, Yajun Wang, Ruifeng Huang, Jun Yang, Xichun Tian, Can Ming, and Shan Guo. Stability analysis and monitoring method for the key block structure of the basic roof of noncoal pillar mining with automatically formed gob-side entry [J]. Advances in Civil Engineering, 2019: 1-14.

[10] Hu, Jinzhu, Zhang, Xingyu, Gao, Yubing, Ma Zimin, Xu Xinzeng, Zhang Xiuping. Directional presplit blasting in an innovative no-pillar mining approach [J]. Journal of Geophysics and Engineering, 2019, 16 (5): 875-893.

[11] Wang Qi, Jiang Bei, Pan Rui, Li Shucai, He Manchao, Sun Huibin, Qin Qian, Yu Hengchang, Luan Yincheng. Failure mechanism of surrounding rock with high stress and confined concrete support system [J]. Int J Rock Mech Min Sci, 2018, 102: 89-100.

[12] Zimin Ma, Jiong Wang, Manchao He, Yubing Gao, Jinzhu Hu, Qiong Wang. Key technologies and application test of an innovative noncoal pillar mining approach: a case study [J]. Energies, 2018, 11: 2853-2875.

[13] Jinzhu Hu, Manchao He, Jiong Wang, Zimin Ma, Yajun Wang, Xingyu Zhang. Key parameters of roof cutting of gob-side entry retaining in a deep inclined thick coal seam with hard roof [J]. Energies, 2019, 12 (5).

[14] Qi Wang, Bei Jiang, Lei Wang, Bohong Liu, Shucai Li, Hongke Gao, Yue Wang. Control mechanism of roof fracture in no-pillar roadways automatically formed by roof cutting and pressure releasing $[\mathrm{J}]$. Arabian Journal of Geosciences, 2020, $13(6)$. 
[15] Zhang Guofend, He Manchao, Yu Xuping, Huang Zhenggu. Research on the technique of no-pillar mining with gob-side entry formed by advanced roof caving in the protective seam in baijiao coal mine [J]. Journal of Mining\&Safety Engineering, 2011, 28 (04): 511-516. (in Chinese).

[16] Manchao He, Yubing Gao, Jun Yang, Weili Gong. An innovative approach for gob-side entry retaining in thick coal seam longwall mining [J]. Energies, 2017, 10 (11).

[17] Yajun Wang, Manchao He, Jun Yang, Qi Wang, Jianning Liu, Xichun Tian, Yubing Gao. Case study on pressure-relief mining technology without advance tunneling and coal pillars in longwall mining [J]. Tunnelling and Underground Space Technology, 2020.

[18] Wenlong Shen, Jianbiao Bai, Xiangyu Wang, Yang Yu. Response and control technology for entry loaded by mining abutment stress of a thick hard roof [J]. International Journal of Rock Mechanics and Mining Sciences, 2016, 90: 26-34.

[19] Qingsheng Bai, Shihao Tu, Fangtian Wang, Cun Zhang. Field and numerical investigations of gateroad system failure induced by hard roofs in a longwall top coal caving face [J]. International Journal of Coal Geology, 2017, 173: 176-199.

[20] Huang Bingxiang, Liu Jiangwei, Zhang Quan. The reasonable breaking location of overhanging hard roof for directional hydraulic fracturing to control strong strata behaviors of gob-side entry [J]. International Journal of Rock Mechanics and Mining Sciences, 2018: 1-11.

[21] Li Yingfu, Hua Xinzhu, Cai Ruichun. Mechanics analysis on the stability of key block in the gob-side entry retaining and engineering application [J]. Journal of Mining \& Safety Engineering, 2012, 29 (3): 357-364. (in Chinese)

[22] LI Xuehua. Control theory and technology of surrounding rock stability for gob-side entry driving in fully mechanized caving mining [M]. Xuzhou: China University of Mining and Technology Press, 2008. (in Chinese)

[23] Han Changliang, Zhang Nong, Li Guichen, Li Baoyu, Wu Hai. Stability analysis of compound bearing structure of gob-side entry retaining with large mining height $[\mathrm{J}]$. Chinese Journal of Geotechnical Engineering, 2014, 36 (5): 969-976. (in Chinese)

[24] Guo Zhibiao, Wang Jiang, Cao Tianpei, Chen Lian, Wang Jiong. Research on key parameters of gob-side entry retaining automatically formed by roof cutting and pressure release in thin coal seam mining [J]. Journal of China University of Mining \& Technology, 2016, 45 (05): 879-885. (in Chinese)

[25] Sun Xiaoming, Liu Xin, Liang Guangfeng, Wang Dong, Jiang Yulin. Key parameters of gob-side entry retaining formed by roof cut and pressure releasing in thin coal seams $[\mathrm{J}]$. Chinese Journal of Rock Mechanics and Engineering, 2014, 33 (07): 1449-1456. (in Chinese). 